\title{
Two cases of COPD benefitting from therapy with roflumilast
}

\author{
Chiara Francesca Carraro ${ }^{*}$
}

\begin{abstract}
Two cases of COPD benefitting from therapy with roflumilast. C.F. Carraro.

Two clinical cases of chronic obstructive pulmonary disease (COPD) stage II patients are reported here. One case refers to a patient with hypoxemia associated to severe air flow limitation, chronic bronchitis and frequent exacerbation events. A significant improvement of patient's con-
\end{abstract}

ditions was observed after pharmacological treatment with roflumilast. The second case refers to a patient who refused to adhere to prescribed therapy but adhered to roflumilast therapy, eventually achieving a good response. Both cases highlight roflumilast's efficacy in improving health conditions of COPD patients.

Monaldi Arch Chest Dis 2013; 79: 3-4, Suppl., 23-28.

Keywords: Roflumilast, COPD, Case report, Hypoxemia, Bronchitis.

1 Pneumology Clinic, ASL TO4, Civil Hospital of Chivasso (TO), Italy.

Correspondence: Dr. Chiara Francesca Carraro, MD, Ambulatorio di Pneumologia, ASL TO4, Ospedale Civile di Chivasso, Corso Galileo Ferraris 3, 10034 Chivasso (TO), Italy; e-mail: ch_carraro@libero.it

\section{Introduction}

Chronic obstructive pulmonary disease (COPD) is characterized by persistent airflow limitation. It is mainly caused by tobacco smoke, with a number of other factors (e.g. air pollution, occupational exposure to dusts and genetics) playing a less common role. The airflow reduction is poorly reversible and usually deteriorates over time. Moreover, the disease is generally associated with an abnormal inflammatory response in the lung after exposure to dusts or noxious gases.
COPD is one of the main causes of death worldwide, ranked by the "World Health Organization" as the fourth leading cause of death. In many countries, the prevalence and mortality of COPD are expected to increase in the next 5-10 years, mainly due to an aging population. COPD is thus expected to become the third leading cause of death in 2020, with tumors and cardiovascular disease being the first and second leading causes, respectively [1]. Diagnosis of COPD, evaluation of the severity of the disease and therapy are mainly dependent on the evaluation of the impairment of bronchial function,

This work originated from the Pneumology Clinic of the Civil Hospital of Chivasso, Corso Galileo Ferraris 3 , 10034 Chivasso (TO), Italy, and has been supported by a grant from Takeda Italia SpA.

* The author received a consultancy fee from Takeda Italia SpA for clinical data collection.

Editorial assistance was provided by Daria Bottai, PhD and Selene Mogavero, PhD (Primula Multimedia SrL) and was sponsored by Takeda Italia SpA. 
shortness of breath, chronic cough or sputum production [1, 2].

A peculiar phenotype of COPD has recently been described, referred to as "COPD frequent exacerbator phenotype". In frequent exacerbator patients, the disease is characterized by recurrent exacerbation events which are repeated over the years and cause a faster impairment of lung function and accelerated disease progression. The recent "ECLIPSE" study demonstrated that in these patients the increased frequency is stable over a 3 -year period, independent of the severity of the disease. It is therefore necessary to correctly identify these patients and develop new and more efficient prevention strategies [3].

Roflumilast, a selective, long-acting phosphodiesterase-4 inhibitor, is a new antiinflammatory drug recommended for the treatment of severe COPD associated with chronic bronchitis. It can often be used as an "add-on" therapy to long acting bronchodilator (BD). The efficacy and safety of roflumilast $(500 \mu \mathrm{g}$ per os daily) for treatment of COPD has been demonstrated by several placebo-controlled, double-blind, randomised clinical studies [4-7]. A recent clinical study demonstrated that roflumilast is able to improve lung function in COPD patients with chronic bronchitis relative to placebo-treated individuals, as indicated by a $48 \mathrm{ml}$ and $55 \mathrm{ml}$ increase of pre-BD and post-BD forced expiratory volume in the first second $\left(\mathrm{FEV}_{1}\right)$ values, respectively. After a treatment period of 1-year, the exacerbation rates per patient per year were 1.14 and 1.37 in roflumilast-treated and placebo-treated patients, respectively. Treatment with roflumilast resulted in a $17 \%$ reduction of the exacerbation rate compared to placebo-treatment [6]. Bateman and coworkers recently performed a predefined post-hoc analysis of M124 and M-125 studies [8], in order to evaluate the efficacy and safety of roflumilast, used in association with long-acting $\beta(2)$-agonists (LABAs), in reducing the frequency and severity of exacerbation events. Roflu- milast reduced the rate of moderate or severe exacerbations, with ratio values of 0.79 and 0.85 with and without LABAs, respectively. These data indicate that roflumilast reduces exacerbations and improves lung function in patients receiving concomitant LABAs [8]. In a different post-hoc analysis performed on M2-124 and M2-125 studies, Wedzicha and coworkers evaluated the effect of roflumilast on exacerbation status, demonstrating that the treatment with roflumilast shifts patients with symptomatic COPD and chronic bronchitis from the frequent to the more stable infrequent exacerbator state. Among frequent exacerbator patients (defined as those who have had two or more exacerbations in the previous year), who were subjected to treatment with roflumilast, $32 \%$ still had frequent exacerbations at year 1 compared with $40.8 \%$ of placebo-treated patients (risk ratio, 0.799). Among infrequent exacerbators (fewer than two events), $17.5 \%$ of roflumilast-treated patients became frequent exacerbators at year 1 compared with $22.9 \%$ of those taking placebo (risk ratio, 0.768) [9].

We report our experience over 13 months with roflumilast-treated patients.

\section{Case Reports}

At our clinic in Chivasso, 40 patients with severe to very severe COPD (GOLD stage $\mathrm{C}$ or $\mathrm{D}$ ) associated with chronic bronchitis were treated with roflumilast from November 2011 to December 2012. The majority of patients $(33 / 44,82.5 \%)$ were affected by severe COPD $\left(30 \% \leq \mathrm{FEV}_{1}<50 \%\right)$, while $17.5 \%(n=7)$ had an extremely severe form of the disease, with a $\mathrm{FEV}_{1}<30 \%$. Exacerbation events in the previous year were minor in $7.5 \%(\mathrm{n}=3)$ of cases, moderate in $57.5 \%(\mathrm{n}=23)$ of cases, and severe in $35 \%$ $(n=14)$ of cases. After a 3-month treatment period with roflumilast, 28 patients were examined (12 out of 40 patients were not examined after 3 months of treatment, since 9 patients dropped out due to adverse events 
and 3 patients had their visit planned after 6 months of treatment). The majority of patients $(85.7 \%, \mathrm{n}=24)$ self-reported an improvement in quality of life (QoL), and displayed no exacerbation events. In 8 patients $(26.8 \%), \mathrm{FEV}_{1}$ values increased by at least $10 \%$ (figure 1).

The two most interesting clinical cases are described.

\section{Case 1}

Sixty-one year old male, former smoker (100 pack-years). In 2010 the patient arrived at our center presenting COPD (stage II, according to the report from another center, spirometry data was missing at the time) with cough and 2 exacerbations in the last 12 months. Furthermore the patient presented severe obesity and arterial hypertension. The pharmacological therapy for COPD consisted in salmeterol/fluticasone $(50 / 500 \mu \mathrm{g}$ twice daily - bid), tiotropium (18 $\mu \mathrm{g} /$ day) and theophylline (300 mg/day). In addition, he was on nocturnal non-invasive mechanical ventilation in association with long-term oxygen therapy.

Blood gas analysis without oxygen supply showed the following parameters: partial pressure of oxygen in arterial blood $\left(\mathrm{PaO}_{2}\right)$ $=55.5 \mathrm{mmHg}$ and a partial pressure of carbon dioxide in arterial blood $\left(\mathrm{PaCO}_{2}\right)=45.8$ $\mathrm{mmHg}$ at the beginning of the therapy; one week after hospitalization $\mathrm{PaO}_{2}$ was 66.2 $\mathrm{mmHg}$ and $\mathrm{PaCO}_{2}$ was $41.9 \mathrm{mmHg}$. No significant improvement in the patient's health conditions evaluated by pulmonary function test and blood gas analysis was observed over a 2-year period. During this time, there was a frequent need for antibiotic therapy due to frequent exacerbations complicated by respiratory failure. In March 2012 the patient was hospitalized due to an extremely severe exacerbation. Spirometry measure-

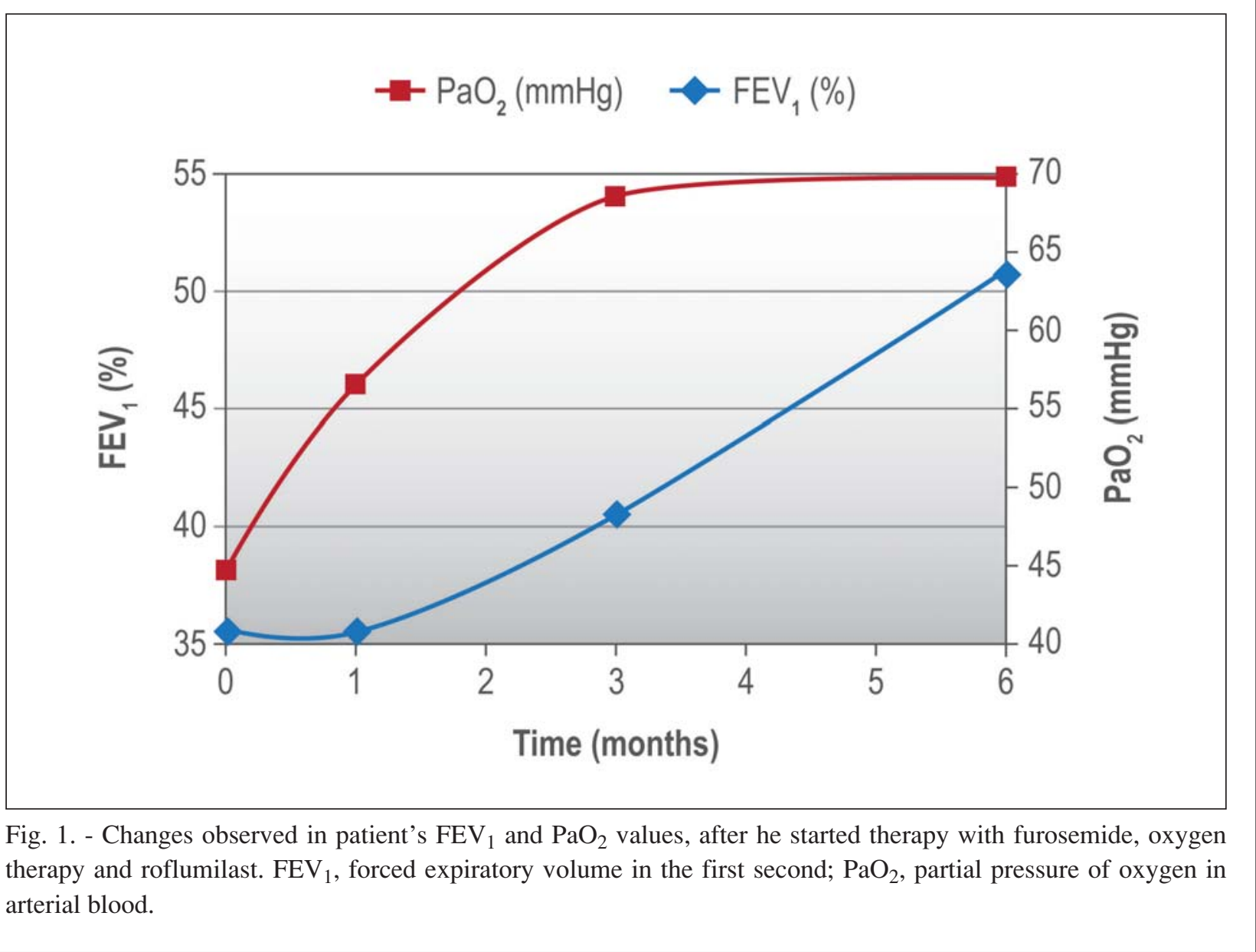


ments confirmed a severe airflow obstruction post-bronchodilator $\left(\mathrm{FEV}_{1} 47.1 \%\right.$; forced vital capacity - FVC 59\%, $\mathrm{FEV}_{1} / \mathrm{FVC}$ $62.71 \%$ ). Modified Medical Research Council Dyspnea Scale score (mMRC) was 4 and the COPD stage (GOLD) was D. The treatment was modified, and theophylline was replaced by roflumilast. After 3 months, spirometry values were: $\mathrm{FEV}_{1} 79.5 \%$, FVC $90.7 \%, \mathrm{FEV}_{1} / \mathrm{FVC} 67.11 \%$. After nine months, the patient displayed the following conditions: i) $\mathrm{FEV}_{1}$ 86.7\%, FVC 101.1.0\%, $\mathrm{FEV}_{1} / \mathrm{FVC} 65.84 \%$ with a significant improvement of spirometry parameters $(84 \%$ increase of $\mathrm{FEV}_{1}$ value compared to that observed at the beginning of treatment); ii) improvement of gas exchange parameters, as shown by blood gas analysis without oxygen supply: $\mathrm{PaO}_{2}=82.7 \mathrm{mmHg}$ and $\mathrm{PaCO}_{2}=$ $38.4 \mathrm{mmHg}$ ); iii) no exacerbation events; $i v$ ) increased resistance to physical effort as spontaneously reported by the patient and as assessed by the mMRC score changing from 4 to $2 ; v$ ) loss of body weight (from 115 to $100 \mathrm{~kg}$ with a shift of body mass index - BMI from 42.24 to 36.73 ).

The $10 \%$ weight loss could have been due both to the drug and to the increased physical activity following the improvement in pulmonary function.

\section{Case 2}

Fifty-eight year old man, smoker since adolescence (40 cigarettes/day, 90 packyears), with no significant occupational exposure to COPD-causing risk factors. In 2006 he had been diagnosed with COPD (stage II according to the report from another center, spirometry data was missing at the time), but he was not compliant to the prescribed BD therapy.

In 2009, he was diagnosed with ischemic heart disease (he underwent percutaneous angioplasty and stenting), arterial hypertension, hypothyroidism and obesity (BMI 30.49). Different tests were performed, in- cluding polysomnography and lung function tests. While no Obstructive Sleep Apnea Syndrome (OSAS) was observed, a nocturnal hypoxemia was detected, by nocturnal saturimetry (mean nocturnal saturimetry $=$ $88.9 \%$, Hypoxiemia Index $=56 \%$ ). Moreover, the post-BD spirometry showed a severe obstructive pattern, $\left(\mathrm{FEV}_{1} 42.3 \%\right.$, FVC $60 \%, \mathrm{FEV}_{1} / \mathrm{FVC} 51.43 \%, \mathrm{mMRC}=3$, COPD stage D). The patient was prescribed with nocturnal oxygen therapy (which was refused) and pharmacological treatment with salmeterol/fluticasone $(50 / 500 \mu \mathrm{g}$, bid). In 2010, 3 exacerbations occurred. Blood gas analysis without oxygen supply values were the following: $\mathrm{PaO}_{2}=65.5 \mathrm{mmHg}, \mathrm{PaCO}_{2}$ $=46.5 \mathrm{mmHg}$, pH 7.404. Pharmacological treatment was modified, and salmeterol/fluticasone were replaced by budesonide/formoterol (320/9 $\mu \mathrm{g}$, bid) and tiotropium (18 $\mu \mathrm{g} /$ day). Cardiological and ergometrical parameters were normal.

After two months, spirometry still showed a severe obstructive pattern $\left(\mathrm{FEV}_{1}\right.$ 45.2\%, FVC 61.7\%, $\mathrm{FEV}_{1} / \mathrm{FVC} 58.01 \%$ ); blood gas analysis without oxygen supply values were: $\mathrm{PaO}_{2}=69.6 \mathrm{mmHg}, \mathrm{PaCO}_{2}$ $=40.8 \mathrm{mmHg}$, $\mathrm{pH} 7.41$ and $\mathrm{Hb}=17.9$. The patient never quit smoking. Dyspnea was assessed through mMRC (value $=3$ ).

In March 2012, a further reduction of the spirometric parameters was observed, as revealed by spirometry $\left(\mathrm{FEV}_{1} 35.6 \%\right.$, FVC $\left.47.5 \%, \mathrm{FEV}_{1} / \mathrm{FVC} 55.93 \%\right)$ and blood gas analysis without oxygen supply $\left(\mathrm{PaO}_{2}=44.9\right.$ $\mathrm{mmHg}, \mathrm{PaCO}_{2}=58.6 \mathrm{mmHg}$ and $\mathrm{pH}=$ 7.372 ). Dyspnea worsened, $m M R C=4$. No infective foci were detected by chest-x-ray. The pharmacological treatment was thus modified by the addition of furosemide (25 mg daily), oxygen therapy (1 L/min, 18 $\mathrm{h} /$ day and $1,5 \mathrm{~L} / \mathrm{min}$ in stress conditions) and roflumilast. One month later (April 2012), an improvement of patient's self-reported health conditions was observed, and confirmed by blood gas analysis without oxygen supply values $\left(\mathrm{PaO}_{2} 56.5 \mathrm{mmHg}, \mathrm{PaCO}_{2}\right.$ 
$55.2 \mathrm{mmHg}$ and $\mathrm{pH}$ 7.397). Spirometry parameters were unchanged. However, side effects, mainly consisting in 2-3 diarrheic events/day, were reported. The increasing improvement of patient's conditions was further observed two months later (June 2012). The blood gas analysis without oxygen supply values were: $\mathrm{PaO}_{2}=68.5 \mathrm{mmHg}, \mathrm{PaCO}_{2}$ $=48 \mathrm{mmHg}, \mathrm{pH} 7.416$; spirometry parameters were: $\mathrm{FEV}_{1} 40.5 \%$, FVC $56.9 \%$, $\mathrm{FEV}_{1} / \mathrm{FVC} 56.52 \%$. No exacerbation events were reported. Moreover, the patient declared increased exercise capacity and tolerance to physical effort $(\mathrm{mMRC}=3)$.

The progressive improvement of patient's conditions was confirmed in September 2012 (alternative Figure 1). Blood gas analysis without oxygen supply values were: $\mathrm{PaO}_{2}$ $=69.8 \mathrm{mmHg}, \mathrm{PaCO}_{2}=39 \mathrm{mmHg}, \mathrm{pH}$ 7.419, $\mathrm{HbCO}_{2} 6.2$; spirometry parameters were: $\mathrm{FEV}_{1} 50.8 \%$, FVC $72.2 \%, \mathrm{FEV}_{1} / \mathrm{FVC}$ $55.84 \%$, Dyspnea assessment: $\mathrm{mMRC}=1$. According to the GOLD guidelines, the COPD was thus classified as GOLD stage A. The gastrointestinal side effects were no more reported.

\section{Discussion}

It is well established that the risk of alveolar hypoxia and consequent hypoxemia increases concomitantly with the progressive severity of COPD disease and loss of pulmonary function [1]. Chronic hypoxemia is strongly associated with the development of adverse sequelae of COPD, such as pulmonary hypertension, secondary polycythemia and systemic inflammation. The combination of all these factors leads to diminished QoL, reduced exercise tolerance, increased risk of cardiovascular morbidity and greater risk of death [10]. In addition, it has been demonstrated that patients with previous exacerbation of COPD, hypercapnia and hypoxemia had the highest risk of an unfavorable evolution of the disease [11].
Both clinical cases described in this report displayed airflow limitation associated with loss of pulmonary function. In both cases, the therapeutic regime included oxygen therapy.

However, for the first case, despite the oxygen therapy, hypoxemia associated to severe obstructive pattern and frequent exacerbation events occurred. A significant improvement of patient's conditions was observed after pharmacological treatment with roflumilast. After a 9-month period, $\mathrm{FEV}_{1}$ values increased from $47.1 \%$ to $86.7 \%$ of predicted values. Consistently, an increase of oxyemic values was detected: the $\mathrm{PaO}_{2}$ shifted from 66.2 to $82.7 \mathrm{mmHg}$. Importantly, no exacerbation events were observed over the same time-period. In agreement to previous studies [12, 13], some effects on body composition have been observed in this patient as a consequence of roflumilast therapy. As observed in several epidemiological studies, the loss of body weight in overweight or obese patients is often associated with an improvement in spirometry parameters and lung function in COPD patients with chronic bronchitis phenotype [13].

In the second case, the unfavorable progression of the disease observed at the beginning of treatment was mainly due to the patient's refusal to comply to the prescribed therapy. The improvement in patient's conditions following roflumilast treatment might be initially attributable to corrections of the pulmonary circulation overload. The stability of blood gas and spirometry parameters are indeed correlated with a favorable response to roflumilast therapy. Gastrointestinal side effects were only transitory.

\section{Riassunto}

Sono qui riportati due casi clinici di pazienti con bronco pneumopatia cronica ostruttiva (BPCO). Un caso si riferisce ad un paziente con ipossiemia associata a grave ostruzione bronchiale, bron- 
chite cronica e frequenti riacutizzazioni. Dopo trattamento farmacologico con roflumilast, è stata osservato un miglioramento significativo delle condizioni del paziente. Il secondo caso si riferisce ad un paziente che si rifiutava di aderire alla terapia prescritta, ma che aderiva alla terapia con roflumilast, ottenendo alla fine una buona risposta alla terapia. Entrambi i casi evidenziano l'efficacia di roflumilast nel migliorare le condizioni di salute di pazienti con BPCO.

Parole chiave: Roflumilast, BPCO, Caso clinico, Ipossiemia, Bronchite.

\section{References}

1. Global Initiative for Chronic Obstructive Lung Disease (GOLD). Global Strategy for the Diagnosis, Management and Prevention of COPD. 2013. Available at www.goldcopd.org.

2. Agusti A, Calverley PMA, Celli B, et al. Characterisation of COPD heterogeneity in the ECLIPSE cohort. Respir Res 2010; 11:122.

3. Hurst JR, Vestbo J, Anzueto A, et al. Susceptibility to exacerbation in chronic obstructive pulmonary disease. N Engl J Med 2010; 363:1128-1138.

4. Rabe KF, Bateman ED, O'Donnell D, et al. Roflumilast - an oral anti-inflammatory treatment for chronic obstructive pulmonary disease: a randomised controlled trial. Lancet 2005; 366 (9485): 563-571.

5. Calverley PMA, Sanchez-Toril F, McIvor A, et al. Effect of 1-year treatment with roflumilast in severe chronic obstructive pulmonary disease. Am J Respir Crit Care Med 2007; 176: 154-161.

6. Calverley PMA, Rabe KF, Goehring U-M, et al. Roflumilast in symptomatic chronic obstructive pulmonary disease: two randomised clinical trials. Lancet 2009; 374 (9691): 685-694.

7. Fabbri LM, Calverley PMA, Izquierdo-Alonso $\mathrm{JL}$, et al. Roflumilast in moderate-to-severe chronic obstructive pulmonary disease treated with longacting bronchodilators: two randomised clinical trials. Lancet 2009; 374 (9691): 695-703.

8. Bateman ED, Rabe KF, Calverley PMA, et al. Roflumilast with long-acting $\beta 2$-agonists for COPD: influence of exacerbation history. Eur Respir J 2011; 38: 553-560.

9. Wedzicha JA, Rabe KF, Martinez FJ, et al. Efficacy of roflumilast in the COPD frequent exacerbator phenotype. Chest 2013; 143: 1302-1311.

10. Kent BD, Mitchell PD, McNicholas WT. Hypoxemia in patients with COPD: cause, effects, and disease progression. Int J Chron Obstruct Pulmon Dis 2011; 6: 199-208.

11. Matkovic Z, Huerta A, Soler N, et al. Predictors of adverse outcome in patients hospitalised for exacerbation of chronic obstructive pulmonary disease. Respiration 2012; 84: 17-26.

12. Wouters EFM, Teichmann P, Brose M, et al. Effects of Roflumilast, a Phosphodiesterase 4 Inhibitor, on Body Composition in Chronic Obstructive Pulmonary Disease. American Thoracic Society 2010; A4473-A4473.

13. Pistelli F, Carrozzi L, Di Pede F, et al. Effects of BMI changes on lung function in COPD subjects from two longitudinal general population studies, Eur Respir J 2012; 40 Suppl: p. 625. 